\title{
Revision of the Japanese Industrial Standardization Act
}

\author{
Ko Ozaki ${ }^{1}$ \\ ${ }^{1}$ Standardization Strategy Section, Ministry of Economy, Trade and Industry (METI), Japan
}

\begin{abstract}
METI is, as of the beginning of May 2018, in the process of revising the Japanese Industrial Standardization Act which was enacted in 1949 and has supported Japan's standardization system for almost 70 years. Objectives of the revision are: 1) expansion of the scope into services and other sectors, 2) acceleration of the JIS development process, 3) promotion of international standardization activities, and 4) enhancement of penalties. The new act is expected to come into effect in the latter half of 2019 if it is passed through the Japanese Diet as planned. By making use of the new system, Japan will strengthen both domestic and international standardization activities.
\end{abstract}

\section{Outline of the Japanese Industrial Standardization Act and background of the revision of the act}

\subsection{Outline of the Japanese Industrial Standardization Act}

The Japanese Industrial Standardization Act (JIS Act) [1], which was enacted in 1949 to improve quality and rationalize production of mineral and industrial products, has played a significant role in Japan's standardization. Specifically, it gives legal basis to: the Japanese Industrial Standards Committee (JISC) [2], Japan's national standardization body; the Japanese Industrial Standard (JIS), Japan's national standard; and the JIS mark and Japan National Laboratory Accreditation System (JNLA), Japan's national conformity assessment systems. As of December 2017, there were 10,622 active JIS based on the Act. In addition, as of March 2018, there were 24 JIS-accredited certification bodies, including three outside of Japan, which have issued about 8,700 certifications for JIS Marks [3].

\subsection{Background of the revision of the Japanese Industrial Standardization Act}

While the importance of the JIS Act has not changed, Japan recognizes that the Act should be revised given the recent trends in standardization activities. First, the scope of the Act, which currently focuses on mineral and industrial products, is too narrow and should be expanded to include services and other sectors in line with international standards. Second, Japan should accelerate the development of JIS given that the development process of international standards, as well as the development of new technologies, has become faster. 
Third, while Japan has been active in contributing to and participating in international standardization activities, the current JIS Act primarily focuses on domestic standardization in Japan, and thus increased efforts are needed to put emphasis on international standardization. Finally, in light of several quality management misconducts by Japanese manufacturing companies, Japan is fully aware that it must take measures that can secure credibility for JIS and the Japanese manufacturing industry. To this end, the Japanese government submitted a bill that aims to revise the JIS Act to the Diet on February 27, 2018. [4]

\section{Revisions of the Japanese Industrial Standardization Act}

\subsection{Expansion of the scope into Services and other sectors}

The revised act is to newly entitle (digital) data, services, and management systems as targets of standardization under JIS. With regard to JIS for data and management systems, Japan has already undertaken considerable development in this area based on the interpretation of the JIS Act that these JIS are within the scope of "industrial products." However, Japan recognizes that, given that the variety of standards regarding data and management systems have been increasing internationally, it would be difficult to maintain adequate coverage with the current flexible interpretation of the JIS Act. (For e.g., it would be difficult to envision a management system standard specifically for services falling within the scope of standards for industrial products). Thus, Japan plans to clearly define that the JIS Act covers standards for data and management systems. In addition, services standards will be added to the scope of JIS. It will allow Japan to contribute to international discussions of services standards more actively. It should be noted that Japan is also planning to design JIS Mark systems for data and services and stipulate it in the revised act.

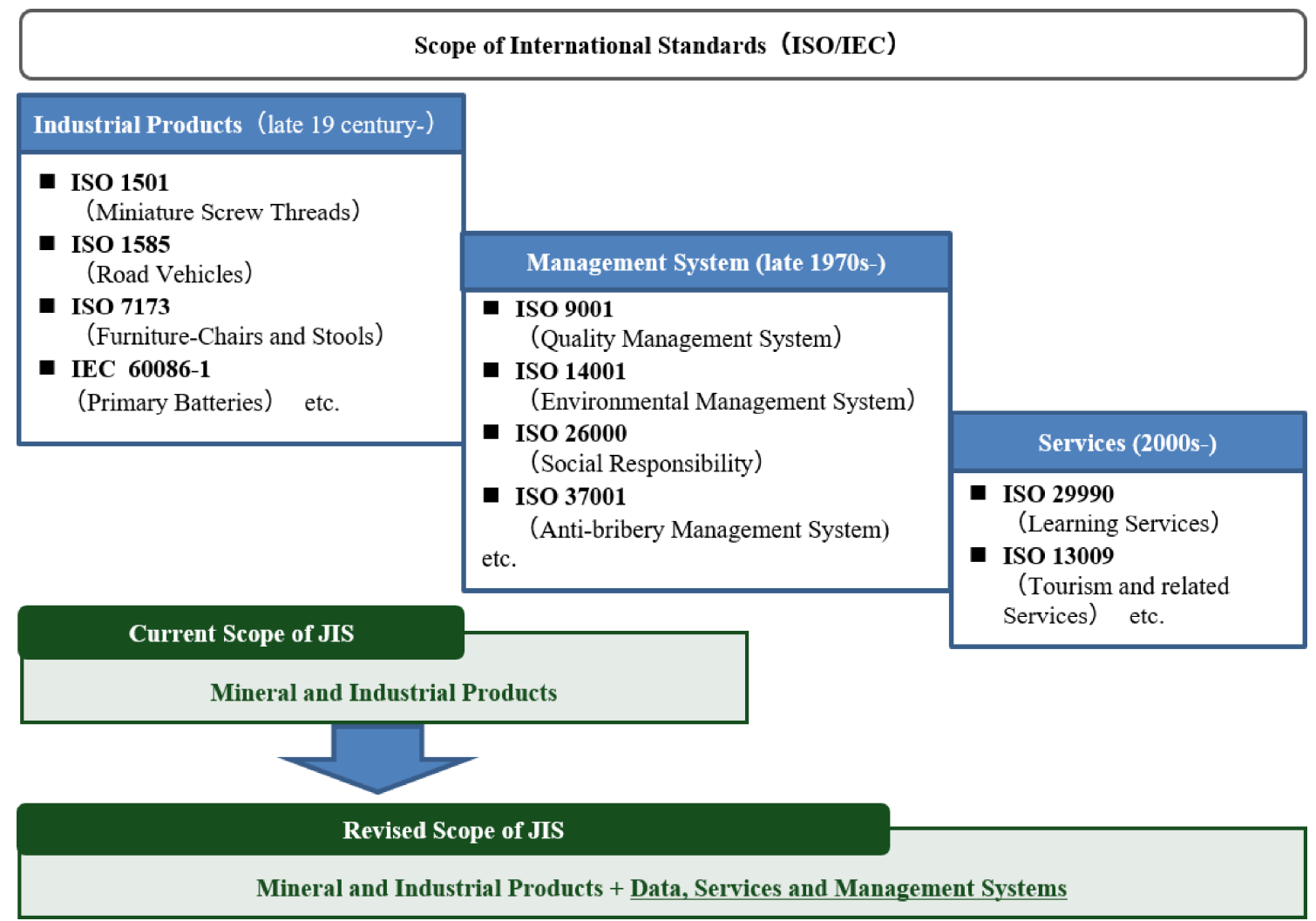

Fig. 1. Scope of International Standards and JIS. 


\subsection{Acceleration of the JIS development process}

The revised act is to allow private associations with expertise to develop JIS without being reviewed by JISC. This new scheme is expected to accelerate the development of JIS. Currently, an individual or organization that aims to develop a JIS needs to form a drafting committee, draft the JIS in the committee, and submit the JIS draft to competent ministers of the Japanese government. Then the competent ministers request JISC to deliberate the draft and, if authorization committees or technical committees under JISC, which comprise of various stakeholders with varied interests in the JIS, consider the draft appropriate, the ministers enact the JIS.

On the other hand, in the new scheme, the deliberation process is entrusted to accredited private entities with expertise, which can be, for instance, industrial associations that have developed a large number of JIS in the past. This means that the accredited private entities are expected to play roles that JISC plays in the current process, such as drafting appropriate JIS while putting diverse opinions from various stakeholders together. Under such condition, JIS drafts written by accredited private entities are not discussed in JISC and competent ministers enact the JIS as soon as the entities submit JIS drafts and the ministers confirm that the drafts are appropriate.

It is expected that, while the period from drafting JIS to enacting it is about two years on average under the current scheme, the period may be shortened under the new scheme. It should be noted, finally, that the current JISC scheme will not be abolished, and stakeholders can select either the current scheme or new scheme based on their preferences.

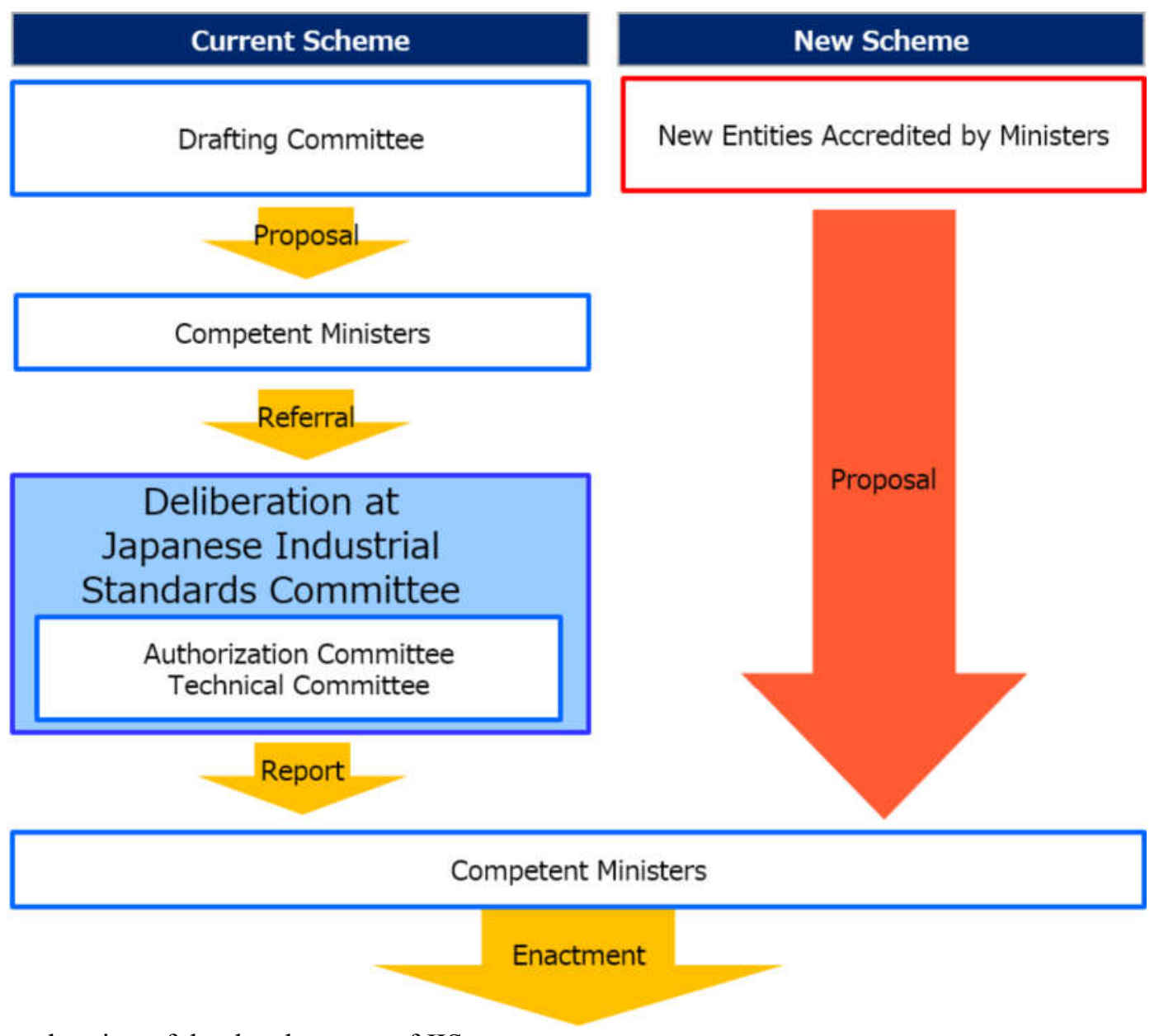

Fig. 2. Acceleration of the development of JIS. 


\subsection{Promotion of International Standardization Activities}

As one of its core purposes, the revised act is to define promotion of international standardization activities. While JISC has actively contributed to international standardization activities in the International Organization for Standardization (ISO) and the International Electrotechnical Commission (IEC), the current JIS Act focuses on national standardization and does not clearly stipulate international standardization. However, given that the significance of international standardization activities for Japan as well as the importance of the harmonization of JIS with international standards have grown significantly, Japan recognizes that it is appropriate to place increased emphasis on the importance of international standardization activities in the JIS Act. Therefore, the revised act is to define promotion of international standardization activities as one of its purposes. Also, it is to stipulate that the government, research institutions, and companies are obligated to make a sincere effort regarding national and international standardization activities.

\subsection{Enhancement of Penalties}

Along with the three proposals for revision outlined above, the upper amount of the fine for unauthorized labeling of JIS mark is to be increased from the current one million yen to 100 million yen. This is one of the measures that the Japanese government will take in order to respond to recent misconducts, which include breaches of rules for JIS marks, committed by several Japanese manufacturing companies. The Japanese government expects that this measure will mitigate the risk of future misconducts related to JIS and assure credibility of JIS.

\section{Making Use of the New System}

The new JIS Act is expected to come into effect in the latter half of 2019 if it is passed through the Japanese Diet as planned. While it would take one to two years until the act comes into effect, Japan has already started to work on measures that it can take. For example, JISC proposed international standardization of temperature-controlled refrigerated delivery services to ISO and it has been under discussions in PC 315 [4]. As this example shows, Japan will strengthen its contribution to standardization activities for services as well as international standardization activities in general.

Having said that, Japan has fully recognized that it needs to take measures besides the revision of the JIS Act in order to make the new systems work. For instance, capacity building for experts and organizations that develop service standards could be one of the challenges for Japan. Japan understands that the number of human resources and organizations for the standardization of services is limited partly because such standardization has largely fallen outside the scope of the JIS Act. Thus, Japan aims to take comprehensive measures that include financial support for the development of standards and training programs for experts. Of course, Japan's measures will not be limited to those for standardization of services, and it will take other measures necessary to make the new systems work.

\section{References}

1. Ministry of Justice, Industrial Standardization http://www.japaneselawtranslation.go.jp/law/detail/?id $=20 \& v m=04 \& r e=02$ 
2. JISC, Japan and Industrial Standards, 4-5 (2017)

http://www.jisc.go.jp/eng/policy/Japan_and_Industrial_Standards_2017.pdf

3. METI, Cabinet Decision on the Bill for the Act of Partial Revision of the Unfair Competition Prevention Act, etc. (2018) http://www.meti.go.jp/english/press/2018/0227_003.html

4. JPO, Promulgation of the Act of Partial Revision of the Unfair Competition Prevention Act, etc.

https://www.jpo.go.jp/torikumi/kaisei/kaisei2/fuseikyousou h300530.htm

5. METI, Aratana Kijun Ninsho No Arikata Nitsuite (JAPANESE) (2017) http://www.meti.go.jp/committee/sankoushin/sangyougijutsu/pdf/006 02 02.pdf 